\title{
A Representação Social dos alunos do Curso Técnico em Agropecuária Integrado ao Ensino Médio do campus Januária do Instituto Federal do Norte de Minas Gerais sobre o ensino remoto no contexto da pandemia da Covid-19
}

\author{
The Social Representation of students of the Technical Course in Agriculture integrated to High
}

School of the Federal Institute of the North of Minas Gerais in Januária campus about remote education in the context of the Covid-19 pandemic

La Representación Social de los estudiantes del Curso Técnico en Agricultura Integrado a la Escuela Secundaria del campus de Januária del Instituto Federal del Norte de Minas Gerais sobre la enseñanza a distancia en el contexto de la pandemia de Covid-19

\section{Resumo}

Este artigo relata os resultados de pesquisa sobre as representações sociais que estudantes do $3^{\circ}$ ano do curso técnico de Agropecuária Integrado ao Ensino Médio do Instituto Federal do Norte de Minas Gerais (IFNMG) - campus Januária apresentam a respeito da dinâmica de suas atividades escolares e extra-escolares na vivência do período de distanciamento social desencadeado pela pandemia do novo coronavírus. Esta investigação, de natureza qualitativa e quantitativa, é realizada mediante a aplicação do método do Discurso do Sujeito Coletivo e apoiada na Teoria das Representações Sociais. Nesse sentido, este trabalho pretende analisar as opiniões desses sujeitos com base em suas percepções, angústias, necessidades e ideais manifestados por eles enquanto observam a realidade mudar repentinamente, além de buscar compreender as mudanças ocasionadas pela interrupção das aulas presenciais e substituição pelo Ensino Remoto Emergencial (ERE). Diante disto, adicionalmente intenciona-se fazer algumas elucidações a fim de estabelecer limites conceituais entre Ensino Remoto Emergencial (ERE) e Educação a Distância (EAD).

Palavras-chave: Covid-19; Ensino; DSC; Representações sociais.

\begin{abstract}
This article describes the research findings on the social representations that 3rd grade integrated secondary education students of Agriculture technical course from Instituto Federal do Norte de Minas Gerais (IFNMG) - campus Januária develop about their school and out-of-school activities dynamics while living in the social distancing policy triggered by coronavirus pandemic. This is a qualitative- quantitative research using the technique of The Discourse of Collective Subject based on the theory of Social Representation. In this regard, this work aims to analyze the opinion of those individuals according to the perceptions, anxieties, needs and ideals voiced by them while they note circumstances suddenly change as well as seek to comprehend the adjustment caused by face-to-face teaching
\end{abstract}


interruption and the implementation of Emergency Remote Teaching (ERE). Additionally, it intends to clarify the concepts of Emergency Remote Teaching (ERE) and Distance Education (EaD).

Keywords: Covid-19; Teaching; DSC; Social representations.

\section{Resumen}

Este artículo reporta los resultados de una investigación sobre las representaciones sociales que los alumnos del 3er año del curso técnico de Agronomía Integrada a la Enseñanza Media del Instituto Federal del Norte de Minas Gerais (IFNMG) - campus de Januária presentan respecto a la dinámica de sus actividades escolares y extraescolares en la experiencia del período de distanciamiento social desencadenado por la pandemia del nuevo coronavirus. Esta investigación, de carácter cualitativo, se realiza aplicando el método del Discurso del Sujeto Colectivo y apoyándose en la Teoría de las Representaciones Sociales. En este sentido, este trabajo pretende analizar las opiniones de estos sujetos a partir de sus percepciones, ansiedades, necesidades e ideales manifestados por ellos al observar la realidad súbitamente cambiante, además de buscar comprender los cambios provocados por la interrupción de las clases presenciales y la sustitución por el Aprendizaje a Distancia de Emergencia (ERE). En vista de ello, se pretende adicionalmente hacer algunas elucidaciones para establecer los límites conceptuales entre la Teleenseñanza de Emergencia (ERE) y la Educación a Distancia (EAD).

Palabras clave: Covid-19; Enseñanza; DSC; Representaciones sociales.

\section{Introdução}

Em 03 de fevereiro de 2020, o Ministério da Saúde, através da Portaria nº 188, declara Emergência em Saúde Pública de importância Nacional (ESPIN) em decorrência da Infecção Humana pelo novo Coronavírus (2019-nCoV), ou Covid-19. Essa medida no âmbito nacional foi uma resposta à Declaração de Emergência em Saúde Pública de Importância Internacional pela Organização Mundial da Saúde (OMS) em 30 de janeiro de 2020. Desde então, o Brasil e o mundo vêm enfrentando diversos desafios advindos do combate à proliferação da doença.

Como forma de enfrentamento, ante a rápida expansão do vírus, o isolamento social foi progressivamente instalando uma nova rotina e, nas escolas e instituições educativas por todo o país, temos visto as aulas presenciais e práticas serem substituídas de forma acelerada por ensino remoto ou aulas online. Tais práticas podem ser nomeadas de diferentes maneiras e, por isso, torna-se necessário estabelecer devida aproximação ou diferenciação entre elas. Neste trabalho, será apresentada a definição de Ensino Remoto e Ensino a Distância (EaD), termos que têm sido usados indistintamente. Outra particularidade decorrente sobretudo da quarentena pode ser melhor observada na rotina de estudantes, pois alguns fatores diretamente relacionados à aprendizagem como a ansiedade, sentimentos de angústia, tristeza, sintomas depressivos e transtorno de déficit de atenção, tornam-se mais presentes em suas vidas, especificamente em alunos do ensino médio, público- alvo da nossa pesquisa, uma vez que é nesse período da vida escolar que os projetos pessoais e profissionais são perspectivados.

Diante disso, este trabalho buscou reconhecer, na fala de um grupo de alunos do $3^{\circ}$ ano do curso técnico em Agropecuária do Ensino Médio Integrado do IFNMG campus Januária, as percepções, as angústias, as necessidades e os ideais desenvolvidos por eles enquanto veem a realidade ao seu redor ser mudada abruptamente.

\section{Metodologia}

Com base no conceito de metodologia entendido por Minayo (2002) como "o caminho do pensamento e a prática exercida na abordagem da realidade", buscou-se, com esta investigação, compreender o contexto e interpretar a realidade de um grupo de alunos do $3^{\circ}$ ano do curso técnico em Agropecuária do Ensino Médio Integrado do IFNMG campus Januária. Para tanto, foi necessária a realização de uma pesquisa de campo que, de acordo com Marconi e Lakatos (2009, p. 186) é aquela utilizada com o objetivo de conseguir informações e/ou conhecimentos acerca de um problema, para o qual se procura uma resposta, ou de uma hipótese, que se queira comprovar, ou, ainda, descobrir novos fenômenos ou as relações entre eles.

Quanto à abordagem, a fim de aprofundar na análise dos fatos apresentados e nas opiniões dos indivíduos, optou-se 
por desenvolver a pesquisa qualitativa que, conforme Pereira et al. (2018), torna-se importante a interpretação por parte do pesquisador com suas opiniões sobre o fenômeno em estudo. Ainda, para o autor,

1) A pesquisa qualitativa, em geral, ocorre no ambiente natural com coleta direta de dados e o pesquisador é o principal instrumento; 2) Os dados coletados são preferencialmente descritivos; 3) A preocupação do processo é predominante em relação à do produto; 4) O "significado" que as pessoas dão as coisas e a sua vida são focos de atenção para o pesquisador e, 5) A análise de dados e informações tende a seguir um processo indutivo. (Pereira, et al., 2018)

Já Minayo (2002) assevera que a pesquisa qualitativa trabalha com o universo de significados, motivos, aspirações, crenças, valores e atitudes, o que corresponde a um espaço mais profundo das relações, dos processos e dos fenômenos que não podem ser reduzidos à operacionalização de variáveis. Em consonância com essa abordagem, utilizou-se como procedimento técnico para coleta de dados um questionário, disponibilizado de forma online ao público alvo por meio de aplicativos de mensagens e e-mail. Para a análise dos dados, realizou-se o método do Discurso do Sujeito Coletivo - DSC (Lefevre \& Lefevre , 2009), que é ancorado na teoria das Representações Sociais de Jodelet (2011).

\section{Resultados e Discussão}

\subsection{EAD e ensino remoto no contexto da Pandemia da Covid-19}

A Covid-19, devido ao alto risco de transmissão pelo contato físico, provocou uma crise na saúde pública e, dentre as medidas profiláticas a serem adotadas pela população na ausência de uma vacina, a mais recomendada, pela maior eficácia de seus efeitos, foi o isolamento social ou físico. Essa decisão foi uma das primeiras medidas adotadas pelos Estados para evitar a eminente pandemia e teve como base as recomendações da Organização Mundial de Saúde (OMS), Organização Panamericana de Saúde (OPAS) e Ministério da Saúde que apontaram o isolamento social como a maior arma para conter a transmissão do SARS-Cov-2.

No Brasil, nesse cenário de pandemia, o Ministério da Educação, por meio da Portaria MEC n. ${ }^{\circ}$ 343, de 17 de março de 2020, alterada pela Portaria MEC n 345 , de 19 de março de 2020, autorizou a substituição das aulas presenciais por aulas mediadas por tecnologias digitais enquanto durar a emergência de saúde pública causada pela Covid-19. Dessa forma, as instituições de ensino presencial tiveram os calendários escolares suspensos para evitar a contaminação dos estudantes e consequentemente dos seus familiares. Atualmente são mais de 47 milhões de alunos sem frequentar os espaços formais de educação e as consequências para esses cidadãos são indeterminadas e não podem ser desconsideradas.

Esse panorama trouxe um contexto de incertezas quanto ao futuro nas realizações pessoais, o que para alguns estudantes configura-se num grande desafio. De acordo com Costa, "a pandemia pode mexer psicologicamente com qualquer pessoa, mas os estudantes precisam colocar em modo de espera seus projetos e, por estarem formando uma carreira, isso pode exacerbar problemas psicológicos já existentes." (Costa, 2020). Com o objetivo de reduzir os potenciais efeitos e prejuízos causados pela crise na educação em decorrência dessa mudança abrupta, grande parte das instituições de ensino no Brasil vem se apoiando nas atividades a distância como estratégia de ensino aprendizagem na Educação Básica. Isto posto, e em meio ao surgimento de novas nomenclaturas que, ao lado da EAD, referem-se a possibilidades para dirimir os efeitos causados pela interrupção das aulas presenciais, entendemos ser conveniente nos atermos a algumas elucidações nesse campo a fim de estabelecer limites conceituais entre Ensino Remoto Emergencial (ERE) e Educação a Distância (EAD).

Ensino Remoto Emergencial, como explicitado pelo próprio nome, refere-se a uma educação a distância, já que os professores e os alunos encontram-se em tempos e espaços diferentes e é de caráter emergencial, ou seja, sua demanda é 
agilizada em virtude de uma mudança repentina e geralmente temporária. Nesses casos, de acordo com Behar (2020), os professores veem-se incapacitados e despreparados, pois saem de uma situação conhecida e confortável e são repentinamente inseridos em um novo modelo de prática mediado por tecnologias. Em contrapartida, a Educação a Distância é uma modalidade educacional regulamentada e prevista no Decreto $n^{\circ}$ 9.057, de 25 de maio de 2017, de onde se lê sua definição:

considera-se educação a distância a modalidade educacional na qual a mediação didático pedagógica nos processos de ensino e aprendizagem ocorra com a utilização de meios e tecnologias de informação e comunicação com pessoal qualificado, com políticas de acesso, com acompanhamento e avaliação compatíveis, entre outros e desenvolva atividades educativas por estudantes e profissionais da educação que estejam em lugares e tempos diversos. (Brasil, 2017)

Embora essa modalidade de ensino seja consolidada, prevista na Lei de Diretrizes e Bases da Educação Nacional e regida por normativas e pareceres, ela ainda suscita muitos questionamentos e, muito frequentemente, torna-se alvo de discussões preconceituosas. Nesse sentido, esclarece Martins (2020) "Como todo preconceito, o direcionado a EAD também vem da falta de conhecimento (...) de como funciona como modalidade. (...) ou de alguma experiência prévia negativa, seja sua ou de outros.". A verdade é que a EAD objetiva incluir, interiorizar o ensino e ampliar as possibilidades para os indivíduos que estão em regiões de difícil acesso. A EAD, praticada com os parâmetros de qualidade estabelecidos em sua constituição, “é um campo específico e ninguém pode negar. (...), um país de dimensões continentais como o nosso, poderá usufruir, em algumas situações, dessa modalidade de ensino." (Moura, 2020). Assim, tendo esclarecido a distância entre os termos, entendese que o que temos visto ocorrer em sua maioria é a aplicação de ERE. Avancemos, então, para outras problemáticas advindas da crise da Covid-19 e seus desdobramentos para a educação.

Considerando a educação como uma mediação da prática social (Saviani, 2020), os desdobramentos no contexto da pandemia devem ser pensados para além do senso comum, partindo da compreensão de que o ser humano, enquanto ser social, produz a sua história, produz a sua existência de forma objetiva por meio do trabalho na relação com outro e com a natureza. Assim, tomar como lente o olhar para a pandemia como algo que nos assola de uma forma violenta nos ajuda a ver que não se trata apenas de uma manifestação da doença, mas que aqui estão implicadas várias questões da vida do ser humano. Ou seja, uma realidade que é uma síntese desse conjunto de relações da existência humana (Ramos, 2020).

A expressão "Fique em casa" tem sido repetida exaustivamente, contudo, em uma sociedade onde as relações acontecem ao sabor do capital, o ficar em casa para o estudante filho do trabalhador tem um gosto amargo, pois escancara os problemas, fruto das desigualdades sociais tão presentes no sistema capitalista que intrinsecamente estão relacionados à educação. O ensino nessa perspectiva, segundo Ramos (2020), traz algumas implicações no espaço das relações familiares. O maior tempo do estudante em casa implica em assumir novos papéis tais como: cuidar dos pais, do irmão menor, dos avós, e tantos outros afazeres que interferem no tempo destinado aos estudos. É bem verdade que o envolvimento das famílias na educação dos jovens é de suma importância para o seu desenvolvimento.

Ademais, em pesquisa realizada por Pedrosa \& Dietz (2021), para alguns pais e responsáveis por estudantes da Educação Básica, essa modalidade de ensino não deveria ser direcionada à esse público, mas sim ao ensino superior, por acreditarem que nesse nível de ensino os discente possuem senso de maturidade. O que não percebem em meio as crianças e jovens na Educação básica em que os valores estão em formação. Entretanto apesar da discordância, compreendem a necessidade devido ao contexto pandêmico imposto.

Nesse aspecto, a Organização da Sociedade Civil, Todos pela Educação, através de sua Nota Técnica, "Ensino a Distância na Educação Básica", vem ressaltar questões consideradas relevantes para melhor relação do envolvimento da família na educação: estimular as expectativas sobre a aprendizagem, buscar a comunicação com frequência a respeito das 
atividades pedagógicas, incentivar hábitos de estudo e leitura são alguns dos principais elementos para mitigar os efeitos negativos diante do quadro atual. Outra implicação importante é a ausência de infraestrutura nas casas dos estudantes, como um espaço adequado para o estudo, o que também está relacionado com a dificuldades na utilização das ferramentas tecnológicas por esses estudantes.

\subsection{Teoria das Representações Sociais e o Discurso do Sujeito Coletivo (DSC)}

A pesquisa qualitativa na educação vem ganhando espaço desde a década de 1980 e propiciando o estudo das percepções pessoais (Bogdan \& Biklen, 1994, p. 11). Ela trabalha (...) "com o universo de significados, motivos, aspirações, crenças, valores e atitudes, o que corresponde a um espaço mais profundo das relações, dos processos e dos fenômenos" (Minayo, 2004, p. 22). Com o desafio de lidar com objetos tão instáveis e, ainda assim manter o rigor da pesquisa científica, é que o Discurso do Sujeito Coletivo (DSC) busca, através da tabulação de dados qualitativos, quantificar ideias, percepções e crenças do coletivo. Essa nova abordagem metodológica é um, ou mais de um, discurso-síntese, que escrito na primeira pessoa, constitui-se de partes de falas de uma coletividade. Desenvolvido por Lefevre e Lefevre, o DSC configura-se sobre a base dos pressupostos da teoria das Representações Sociais.

As Representações Sociais, por sua vez, são fenômenos, esquemas resultantes da cotidiana interação social em que os sujeitos exprimem sentimentos e pontos de vista de situações compartilhadas. Ao recolher os depoimentos, falas com sentidos próximos, e processá-los, o que se consegue, de acordo com Lefevre e Lefevre (2009, p. 1194), é o efeito de "coletividade falando".

Dessa maneira, as Representações Sociais podem ser entendidas como a interpretação que grupos de indivíduos têm acerca da realidade ao interagir com o ambiente do qual faz parte, além de procurar compreender os fenômenos naturais decorrentes dessa interação. Nesse sentido, Jodelet (2011, p. 134) afirma que as Representações Sociais

Correspondem a uma forma específica de conhecimento, conhecimento comum, que é incluído na categoria de senso comum e tem como particularidade o de ser socialmente construído e compartilhado dentro de diferentes grupos. Essa forma de conhecimento tem uma raiz e um objetivo prático: contando com a experiência das pessoas, serve como uma grade de leitura da realidade e guia de ação na vida prática e diária. ${ }^{1}$

As Representações Sociais, nesse contexto, significa que os sujeitos partilham as mesmas ideias, crenças, valores e manifestações culturais do mundo em que vivem e, por consequência, podem ser sintetizadas em discurso único que representa a opinião dessa coletividade, ou seja, o Discurso do Sujeito Coletivo - DSC. O DSC "constitui um novo método [...] para as pesquisas de opinião, de representação social ou, mais genericamente, de atribuição social de sentido, que tenham como material de base depoimentos ou outros suportes de material verbal como matérias de revistas, jornais etc. (Lefevre \& Lefevre, 2012, p. 16). Ademais, tal método

permite um significativo ganho de qualidade nessas pesquisas, já que os resultados podem ser generalizados e aparecem, numa escala coletiva, como uma opinião naturalmente se apresenta, isto é, como depoimento sob a forma de discurso. [...] operações que redundam, ao final do processo, em [...] constructos confeccionados com estratos literais do conteúdo mais significativo dos diferentes depoimentos que apresentam sentidos semelhantes. (Lefevre \& Lefevre, 2012, p. 17)

\footnotetext{
${ }^{1}$ (Jodelet, 2011, Tradução Nossa.)
} 
Com base no método do Discurso do Sujeito Coletivo e suporte teórico da Teoria das Representações Sociais foi realizado o presente trabalho. Desse modo, foi feita uma investigação do tipo pesquisa de campo, de abordagem qualitativa, com a técnica de questionário, disponibilizado de forma online via aplicativos de mensagem, e-mail e ferramentas comunicacionais. O público alvo da pesquisa foi um grupo de alunos do $3^{\circ}$ ano do curso técnico em Agropecuária integrado ao Ensino Médio do campus Januária do Instituto Federal do Norte de Minas Gerais (IFNMG).

Assim, por meio da análise das respostas de cada participante, foram escolhidas as expressões-chave (ECH), que "são pedaços, ou trechos, ou segmentos, contínuos ou descontínuos, do discurso, que devem ser selecionados pelo pesquisador e que revelam a essência do conteúdo do depoimento ou discurso, ou da teoria subjacente.” (Lefevre \& Lefevre, 2012, p. 76), e as ideias centrais (IC) que são "um nome ou expressão linguística que revela e descreve da maneira mais sintética e precisa possível o sentido ou sentidos das ECH de cada um dos discursos analisados e de cada conjunto homogêneo de ECHs (que vai dar nascimento, posteriormente, ao DSC).” (Lefevre \& Lefevre, 2012, p. 76).

Desse modo, as respostas coletadas foram analisadas para identificação das ECHs, mediante o refinamento de seu conteúdo e exclusão do que é irrelevante para construção do DSC. Posteriormente, foram identificadas as ICs de cada resposta para agrupamento em categorias. Para melhor detalhamento, organização e compreensão da análise, as informações foram dispostas em quadros da seguinte maneira: questão 1: quadro 1, questão 2: quadro 2, aluno 1 (A1), aluno 2 (A2); ECH 1, ECH 2; IC, e assim, sucessivamente. Dessa maneira, foram obtidos os DSCs sobre o tema deste trabalho.

Com a adoção da metodologia do DSC, foram analisadas as respostas dos alunos do $3^{\circ}$ ano do curso técnico integrado em Agropecuária para as cinco questões aplicadas em questionário online, disponibilizado via e-mail e aplicativos de mensagens. As ECHs e ICs obtidas estão dispostas nos quadros 1, 2, 3, 4 e 5 a seguir.

Quadro 1. Questão 1: Como sua rotina familiar está sendo afetada nesse período de pandemia do Covid-19?

\begin{tabular}{|c|c|c|c|c|}
\hline Aluno & ECH1 & $\mathrm{ECH} 2$ & IC1 & IC2 \\
\hline A1 & $\begin{array}{l}\text { Não estou tendo grandes } \\
\text { mudanças... }\end{array}$ & - & Sem grandes mudanças & - \\
\hline A2 & $\begin{array}{l}\text { Está normal... não estou tendo } \\
\text { aula remota ... então com isso } \\
\text { ajudo na limpeza e organização } \\
\text { de casa. }\end{array}$ & - & $\begin{array}{l}\text { Normal. Ajuda nas tarefas } \\
\text { domésticas na ausência do ensino } \\
\text { remoto. }\end{array}$ & - \\
\hline A3 & $\begin{array}{l}\text { Está afetando } . . . \\
\text { econômica para } \text { o suestão } \\
\text { família. }\end{array}$ & - & $\begin{array}{l}\text { A pandemia causa dificuldades } \\
\text { financeiras na família. }\end{array}$ & - \\
\hline A4 & $\begin{array}{l}\text {... muito corrida, além de fazer as } \\
\text { tarefas domésticas tenho também } \\
\text { que estudar... por conta disso os } \\
\text { estudos acabam não sendo muito } \\
\text { proveitosos. }\end{array}$ & $\begin{array}{l}\text {... tenho que auxiliar meus } \\
\text { irmãos com os estudos deles } \\
\text {... deixando muitas vezes de } \\
\text { estudar o que eu havia } \\
\text { planejado. }\end{array}$ & $\begin{array}{l}\text { Rotina agitada devido às tarefas } \\
\text { domésticas e estudos. }\end{array}$ & - \\
\hline A5 & $\begin{array}{l}\text {... mudou o fato de estarmos todos } \\
\text { em casa todos os dias. }\end{array}$ & - & $\begin{array}{l}\text { A família fica em casa todos os } \\
\text { dias. }\end{array}$ & - \\
\hline
\end{tabular}


Research, Society and Development, v. 10, n. 2, e59710212923, 2021

(CC BY 4.0) | ISSN 2525-3409 | DOI: http://dx.doi.org/10.33448/rsd-v10i2.12923

\begin{tabular}{|c|l|l|l|l|}
\hline A6 & $\begin{array}{l}\text {... as pessoas tem estado mais } \\
\text { próximas isso me agrada muito. }\end{array}$ & - & As pessoas ficam mais próximas. \\
\hline A7 & $\begin{array}{l}\text { Não estou conseguindo estudar de } \\
\text { forma correta. }\end{array}$ & $\begin{array}{l}\text { Dificuldades de estudar } \\
\text { adequadamente. }\end{array}$ & - \\
\hline A8 & $\begin{array}{l}\text { Meus pais estão trabalhando } \\
\text { normalmente porque ... não temos } \\
\text { a opção de fixar dentro de casa... } \\
\text { em relação a mim e minha irmã, } \\
\text { estamos em casa desde o início... }\end{array}$ & $\begin{array}{l}\text { Os pais trabalham normalmente, os } \\
\text { filhos estão em casa em quarentena. }\end{array}$ & - \\
\hline
\end{tabular}

Fonte: Autores.

O Quadro 1 representa as respostas dos alunos do $3^{\circ}$ ano do curso técnico integrado em Agropecuária e são os dados usados para se obter as expressões-chave e ideias centrais com o intuito de formular os DSCs referentes à questão "Como sua rotina familiar está sendo afetada nesse período de pandemia da Covid-19?". Cabe ressaltar que, de acordo com Lefevre \& Lefevre, as expressões-chave são trechos do discurso que revelam a essência do conteúdo do depoimento do pesquisado e as ideias centrais são um nome ou expressão linguística que revela sinteticamente o sentido ou sentidos das expressões-chave de cada um dos discursos analisados.

Quadro 2. Questão 2: Como tem sido sua rotina de estudos?

\begin{tabular}{|c|c|c|c|c|}
\hline Aluno & ECH1 & $\mathrm{ECH} 2$ & IC1 & IC2 \\
\hline A1 & $\begin{array}{l}\text {... basicamente não estou } \\
\text { estudando... }\end{array}$ & $\begin{array}{l}\text { Sem mente pra isso no } \\
\text { momento... }\end{array}$ & Parou os estudos. & $\begin{array}{l}\text { Sem condições } \\
\text { emocionais. }\end{array}$ \\
\hline $\mathrm{A} 2$ & $\begin{array}{l}\text {... por conta própria, com } \\
\text { videoaulas } \quad \text { gratuitas } \\
\text { YouTube } \mathrm{e} \quad . . \\
\text { recursos } \\
\text { cursos gratuitos... }\end{array}$ & - & $\begin{array}{l}\text { Estuda só por meio de videoaulas } \\
\text { e cursos gratuitos. }\end{array}$ & - \\
\hline A3 & ... está devagar, quase parando. & $\begin{array}{l}\text { Me sinto desmotivada e } \\
\text { desanimada... }\end{array}$ & Está lenta. & $\begin{array}{l}\text { Desmotivada } \\
\text { emocionalmente. }\end{array}$ \\
\hline A4 & Não muito produtiva. & - & Pouco produtiva & - \\
\hline A5 & $\begin{array}{l}\text { Estudo ... no horário em que } \\
\text { estaria na escola. }\end{array}$ & - & Há um horário para estudar. & - \\
\hline A6 & Não posso chamar de rotina ... & $\begin{array}{l}\text {... estou muito abalada por } \\
\text { estudar sozinha... }\end{array}$ & Sem rotina de estudos. & $\begin{array}{l}\text { Abalada } \\
\text { emocionalmente } \\
\text { para estudar. }\end{array}$ \\
\hline A7 & $\begin{array}{l}\text { Não consigo estudar como } \\
\text { antes, ... }\end{array}$ & $\begin{array}{l}\text {... o mínimo possível pois não } \\
\text { tenho algo para me estimular } \\
\text { a estudar. }\end{array}$ & A rotina de estudos mudou. & $\begin{array}{l}\text { Estuda pouco, } \\
\text { pois não se sente } \\
\text { estimulado. }\end{array}$ \\
\hline A8 & $\begin{array}{l}\text { Embora procure estudar por } \\
\text { meio da internet ... não consigo } \\
\text { absorver nem metade do }\end{array}$ & $\begin{array}{l}\text {... não ter certeza de nada me } \\
\text { assusta, ... não estou tendo } \\
\text { base o suficiente para realizar }\end{array}$ & $\begin{array}{l}\text { Tentar estudar, mas se sente } \\
\text { exausta por se pressionar muito, } \\
\text { por isso não consegue assimilar o }\end{array}$ & $\begin{array}{l}\text { Sente-se assustada } \\
\text { e insegura quanto } \\
\text { aor futuro }\end{array}$ \\
\hline
\end{tabular}




\begin{tabular}{|l|l|l|l|l|}
\hline & $\begin{array}{l}\text { conteúdo... a pressão } \\
\text { psicológica que coloco em mim }\end{array}$ & a prova do Enem e não sei & conteúdo. & acadêmico. \\
nesma quando formarei. & para fazer algo & & \\
produtivo ... me deixa exausta & & & \\
as vezes. & & & \\
\hline
\end{tabular}

Fonte: Autores.

O Quadro 2 corresponde às respostas referentes à questão "Como tem sido sua rotina de estudos?" e são os dados necessários à formulação dos DSCs a partir das expressões-chave e ideias centrais que, em alguns casos, podem ocorrer uma ou mais vezes para cada resposta. Nesse sentido, elas revelam a opinião do pesquisado sobre a temática.

Quadro 3. Questão 3: De que forma você está reagindo nos momentos de estudos diante da ausência dos professores e colegas de sala?

\begin{tabular}{|c|c|c|c|c|}
\hline Aluno & ECH1 & $\mathrm{ECH} 2$ & IC1 & IC2 \\
\hline A1 & $\begin{array}{l}\text { Simplesmente não estudando... } \\
\text { sem ânimo. }\end{array}$ & - & Sem ânimo para estudar. & - \\
\hline $\mathrm{A} 2$ & $\begin{array}{l}\text {... perco o foco dos estudos } \\
\text { porque em casa é mais difícil de } \\
\text { se concentrar, ainda mais } \\
\text { quando não se tem ninguém } \\
\text { para te ajudar a se organizar... }\end{array}$ & $\begin{array}{l}\text {... um professor faz falta, é ele } \\
\text { que te da o suporte necessário } \\
\text { para obter um bom } \\
\text { desempenho. }\end{array}$ & $\begin{array}{l}\text { Estudar em casa gera dificuldades } \\
\text { como falta de concentração e de } \\
\text { alguém para ajudar. }\end{array}$ & $\begin{array}{ll}\text { A colaboração do } \\
\text { professor } \\
\text { necessária para } \\
\text { um bom } \\
\text { desempenho } \\
\text { escolar. }\end{array}$ \\
\hline A3 & $\begin{array}{l}\text { Quando estamos acostumados a } \\
\text { uma rotina, ... fica difícil de } \\
\text { adaptar a uma outra. }\end{array}$ & $\begin{array}{l}\text { As aulas presenciais e práticas } \\
\text { fazem total diferença na vida } \\
\text { de um estudante, ainda mais } \\
\text { se ele faz um curso técnico ... }\end{array}$ & $\begin{array}{l}\text { Dificuldade de adaptação de uma } \\
\text { rotina de estudos a outra. }\end{array}$ & $\begin{array}{l}\text { As aulas } \\
\text { presenciais } \mathrm{e} \\
\text { práticas são um } \\
\text { diferencial para o } \\
\text { cursos técnico. }\end{array}$ \\
\hline A4 & $\begin{array}{l}\text {.. esforçando ... para compensar } \\
\text { a ausência dos mesmos, } \\
\text { assistindo videoaulas e fazendo } \\
\text { atividades dos livros didáticos... }\end{array}$ & - & $\begin{array}{l}\text { Tenta compensar a ausência ao } \\
\text { assistir videoaulas e estudar livros } \\
\text { didáticos. }\end{array}$ & - \\
\hline A5 & $\begin{array}{l}\text { Tendo dificuldade, mas procuro } \\
\text { ajuda gratuita na internet. }\end{array}$ & - & Faz pesquisas na internet. & - \\
\hline A6 & 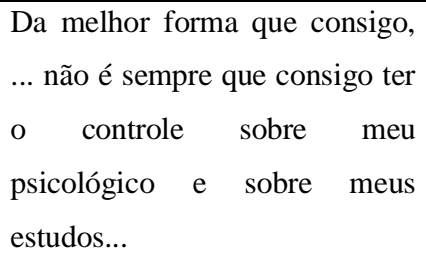 & - & $\begin{array}{l}\text { Encontra dificuldades de controle } \\
\text { emocional para estudar. }\end{array}$ & - \\
\hline A7 & $\begin{array}{l}\text { Procuro pesquisar ... na internet } \\
\text { ou peço a opinião dos meus } \\
\text { pais. }\end{array}$ & $\begin{array}{l}\text {... sempre tem algo que } \ldots \\
\text { apenas os professores } \\
\text { possam } \\
\text { resolver }\end{array}$ & $\begin{array}{l}\text { Faz pesquisas na internet ou pede } \\
\text { ajuda aos pais. }\end{array}$ & $\begin{array}{l}\text { Professores } \\
\text { colegas } \\
\text { contribuem na }\end{array}$ \\
\hline
\end{tabular}




\begin{tabular}{|c|l|l|l|l|}
\hline & & colegas. & & $\begin{array}{c}\text { construção } \\
\text { conhecimento. }\end{array}$ \\
\hline \multirow{3}{*}{ A8 } & $\begin{array}{l}\text {... às vezes até tenho ânimo para } \\
\text { fazer várias coisas, mas tem } \\
\text { dias que a vontade de largar } \\
\text { tudo e ficar deitada é maior... }\end{array}$ & - & $\begin{array}{l}\text { Encontra dificuldades } \\
\text { estudar devido a desânimo. }\end{array}$ & para \\
\hline
\end{tabular}

Fonte: Autores.

O Quadro 3 exprime as expressões-chave e ideias centrais referentes às respostas referentes à questão "De que forma você está reagindo nos momentos de estudos diante da ausência dos professores e colegas de sala?" e objetiva obter nos trechos dos discursos proferidos pelos alunos a essência do tema abordado, a qual representa o cerne dos DSCs a serem elaborados a partir dos depoimentos dos alunos sobre a pergunta.

Quadro 4. Questão 4: Como você e sua família estão reagindo emocionalmente aos efeitos causados por essa situação de pandemia?

\begin{tabular}{|c|c|c|c|c|}
\hline Aluno & ECH1 & $\mathrm{ECH} 2$ & IC1 & IC2 \\
\hline A1 & $\begin{array}{l}\text {... estou bem cansada disso tudo } \\
\text { já, ... minha família também. }\end{array}$ & ... tentando pensar positivo. & $\begin{array}{l}\text { A pessoa e família se sentem } \\
\text { cansadas. }\end{array}$ & $\begin{array}{l}\text { Tentam pensar } \\
\text { positivamente. }\end{array}$ \\
\hline $\mathrm{A} 2$ & $\begin{array}{l}\text {... lidando bem com a situação, } \\
\ldots \quad \text { procuramos não nos } \\
\text { desesperar... }\end{array}$ & - & $\begin{array}{l}\text { Lidam com a situação sem } \\
\text { desesperar. }\end{array}$ & - \\
\hline A3 & $\begin{array}{l}\text {... ficamos apreensivos com tal } \\
\text { situação pois os efeitos ... são } \\
\text { vistos, ... preocupados com os } \\
\text { que estão por vir. }\end{array}$ & - & $\begin{array}{l}\text { Estão preocupados com os efeitos } \\
\text { que estão por vir. }\end{array}$ & - \\
\hline A4 & $\begin{array}{l}\text { Meus pais as vezes estão muito } \\
\text { estressados, eu e meus irmãos } \\
\text { estamos tendo conflitos as } \\
\text { vezes ... }\end{array}$ & $\begin{array}{l}\text {... em relação aos estudos às } \\
\text { vezes são jogados somente } \\
\text { para mim fazendo com que eu } \\
\text { me sinta sobrecarregada e ... } \\
\text { desmotivada ... }\end{array}$ & $\begin{array}{l}\text { Os pais ficam estressados e os } \\
\text { filhos entram em conflito } \\
\text { ocasionalmente. }\end{array}$ & $\begin{array}{l}\text { Sente-se } \\
\text { desmotivada e } \\
\text { sobrecarregada } \\
\text { por acumular } \\
\text { seus estudos e } \\
\text { dos irmãos. }\end{array}$ \\
\hline A5 & Bem. & - & Bem. & - \\
\hline A6 & $\begin{array}{l}\text { Tentamos agir de uma forma } \\
\text { mais leve e descontraída... }\end{array}$ & $\begin{array}{l}\text {... não conversamos muito } \\
\text { sobre esse assunto... }\end{array}$ & $\begin{array}{l}\text { Tentar lidar com leveza e } \\
\text { descontração. }\end{array}$ & $\begin{array}{l}\text { Evitam falar } \\
\text { sobre o assunto. }\end{array}$ \\
\hline A7 & $\begin{array}{l}\text {... tranquilos porém nos } \\
\text { preocupamos em relação os } \\
\text { estudos e renda. }\end{array}$ & - & $\begin{array}{l}\text { Sentem-se tranquilos, mas } \\
\text { preocupam-se com estudos e } \\
\text { renda. }\end{array}$ & - \\
\hline A8 & $\begin{array}{l}\text {... está tudo bem, as vezes ... } \\
\text { bate um certo desespero em } \\
\text { relação a escola, o Enem e a } \\
\text { faculdade ... }\end{array}$ & - & $\begin{array}{l}\text { Sentem-se bem, ocasionalmente } \\
\text { desespera-se em relação ao futuro } \\
\text { acadêmico. }\end{array}$ & - \\
\hline
\end{tabular}

Fonte: Autores. 
O Quadro 4 retrata as respostas dos alunos relativas à questão "Como você e sua família estão reagindo emocionalmente aos efeitos causados por essa situação de pandemia?". Os dados apresentados formam as expressões-chave e ideias centrais, a partir desses depoimentos, que são a base para a elaboração dos DSCs para a pergunta em análise.

Quadro 5. Questão 5: Em relação à expectativa dos seus sonhos ou projetos, como você está lidando com isso nesse contexto de pandemia?

\begin{tabular}{|c|c|c|c|c|}
\hline Aluno & ECH1 & $\mathrm{ECH} 2$ & IC1 & IC2 \\
\hline A1 & $\begin{array}{l}\text { Sem sonhos ou projetos ... tudo } \\
\text { perdeu um pouco de sentido. }\end{array}$ & $\begin{array}{l}\text {... é acreditar que vai ficar } \\
\text { tudo bem.. }\end{array}$ & $\begin{array}{l}\text { Os sonhos e projetos perderam o } \\
\text { sentido. }\end{array}$ & $\begin{array}{l}\text { Há esperança de } \\
\text { que tudo ficará } \\
\text { bem. }\end{array}$ \\
\hline A2 & $\begin{array}{l}\text {... minhas expectativas } \ldots \\
\text { diminuíram por conta de eu não } \\
\text { estar estudando... }\end{array}$ & $\begin{array}{l}\text {.. ainda acredito que } \\
\text { conseguirei tudo, demorará } \\
\text { mais tempo ... }\end{array}$ & $\begin{array}{l}\text { As expectativas mudaram por não } \\
\text { estar estudando. }\end{array}$ & $\begin{array}{ll}\text { Acredita } & \text { que } \\
\text { realizará } & \text { os } \\
\text { sonhos em um } & \\
\text { tempo maior. } & \end{array}$ \\
\hline A3 & $\begin{array}{l}\text {.. pretendo seguir na área do } \\
\text { meu curso técnico em } \\
\text { agropecuária ... }\end{array}$ & $\begin{array}{l}\text {... como alguém vai ... me } \\
\text { contratar sabendo que me } \\
\text { formei ... com aulas remotas, } \\
\text { sem aulas práticas. Isso } \\
\text { desmotiva, me fazendo pensar } \\
\text { em desistir. }\end{array}$ & Pretende seguir na área do curso. & $\begin{array}{l}\text { Há descrédito } \\
\text { sobre coma } \\
\text { formação com } \\
\text { aulas remotas, o } \\
\text { que a desmotiva. }\end{array}$ \\
\hline A4 & $\begin{array}{l}\text { Estou tentado e me esforçando } \\
\ldots \text { para alcança-los ... tento } \\
\text { manter o foco ... }\end{array}$ & - & $\begin{array}{l}\text { Mantém o esforço e foco para } \\
\text { realizar os sonhos. }\end{array}$ & - \\
\hline A5 & $\begin{array}{l}\text { Está sendo frustrante ... no } \\
\text { último ano do ensino médio a } \\
\text { preocupação com a vida } \\
\text { universitária é maior... }\end{array}$ & $\begin{array}{l}\text { Não sabemos ... se vamos } \\
\text { conseguir passar no vestibular } \\
\text { ou } . . . \text { concluir antes do } \\
\text { período de matrícula. }\end{array}$ & $\begin{array}{l}\text { Sente-se frustrada e preocupada } \\
\text { com o futuro acadêmico. }\end{array}$ & $\begin{array}{ll}\text { Tem dúvidas } & \text { se } \\
\text { conseguirá } & \text { ter } \\
\text { êxito } & \text { no } \\
\text { vestibular. } & \end{array}$ \\
\hline A6 & $\begin{array}{l}\text {... muitos sonhos que eu tinha } \\
\text { para esse ano foram frustrados... }\end{array}$ & $\begin{array}{l}\text { agora está sendo uma } \\
\text { experiência de aprendizagem } \\
\text { mútua ... meus sonhos podem } \\
\text { esperar um pouco pensando } \\
\text { no bem maior da sociedade... }\end{array}$ & Os sonhos foram frustrados. & $\begin{array}{l}\text { O momento é de } \\
\text { aprendizagem e os } \\
\text { sonhos podem } \\
\text { esperar em favor } \\
\text { de um bem maior. }\end{array}$ \\
\hline A7 & $\begin{array}{l}\text {... como se nada estivesse no } \\
\text { caminho certo para não serem } \\
\text { concretizados. }\end{array}$ & $\begin{array}{l}\text {... penso que o tempo vai } \\
\text { ajudar... }\end{array}$ & $\begin{array}{l}\text { Sente que os sonhos não se } \\
\text { concretizarão. }\end{array}$ & $\begin{array}{l}\text { O tempo vai } \\
\text { ajudar. }\end{array}$ \\
\hline A8 & $\begin{array}{l}\text { Insegura é a palavra. Creio que } \\
\text { tudo dará certo no tempo de } \\
\text { Deus, mas às vezes bate uma } \\
\text { insegurança... sobre meu futuro } \\
\text { acadêmico ... até o momento } \\
\text { não temos respostas concretas } \\
\text { sobre isso. }\end{array}$ & - & $\begin{array}{l}\text { Sente-se insegura sobre o futuro } \\
\text { acadêmico, mas mantém a fé de } \\
\text { que tudo dará certo. }\end{array}$ & - \\
\hline
\end{tabular}


O Quadro 5 corresponde às respostas referentes à questão "Em relação à expectativa dos seus sonhos ou projetos, como você está lidando com isso nesse contexto de pandemia?" As respostas com depoimentos dos alunos representam os dados necessários para a elaboração dos DSCs para a pergunta em análise, que devem ser obtidos por meio das expressõeschave e ideias centrais formuladas a partir de cada resposta dos alunos.

Desse modo, após a seleção das ECHs, que são o resultado da depuração dos discursos dos sujeitos nas respostas colhidas pelo questionário, chegou-se à identificação das ICs. Posteriormente a esta ação, são criadas as categorias por meio do agrupamento de ICs semelhantes, a partir das quais serão elaborados os DSCs.

Na questão 1 são identificadas as seguintes categorias:

\section{IC1 - Categorias}

A) Sem mudanças significativas;

B) Dificuldades financeiras na família;

C) Rotina agitada devido às tarefas domésticas e dificuldades de estudar adequadamente;

D) As pessoas da família ficam próximas em função da quarentena;

E) Os filhos ficam em quarentena enquanto os pais trabalham.

$\mathrm{Na}$ categoria $\mathrm{A}$, os alunos A1 e A2 relataram não haver mudanças significativas na rotina familiar, embora o aluno A2 afirme que ajuda nas tarefas domésticas na ausência do ensino remoto. Na categoria B, o aluno A3 declarou que a pandemia causa dificuldades financeiras na família, reflexo do agravamento da crise econômica. Na categoria C, os alunos A4 e A7 relataram dificuldades para estudar adequadamente e a rotina agitada pela necessidade de realizar tarefas domésticas. Na categoria D, os alunos A5 e A6 apresentam opiniões semelhantes quanto ao efeito da quarentena provocada pela pandemia, que é a proximidade maior entre os membros das famílias. Na categoria E, o aluno A8 declarou que os pais precisam trabalhar normalmente e não podem ficar em quarentena, porém ele e os irmãos estão desde o início.

Na questão 2 são identificadas as seguintes categorias:

\section{IC1 - Categorias}

F) Mudança na rotina de estudos;

G) Estudar por conta própria;

H) Pressão psicológica para estudar.

\section{IC2 - Categoria}

I) Mudanças emocionais.

Na categoria F, os alunos A1, A3, A4, A6 e A7 afirmam opiniões semelhantes em mudanças na rotina de estudos tais como pouco produtiva, lenta, sem rotina de estudos ou que pararam de estudar. Na categoria G, os alunos A2 e A5 definiram uma rotina ou horário de estudos a qual inclui videoaulas e cursos gratuitos na internet. Na categoria $\mathrm{H}$, o aluno $\mathrm{H}$ relata a tentativa de estudar, mas se sente exausta ao impor a si mesmo uma pressão psicológica por resultado. Na categoria I, os alunos A1, A3, A6, A7 e A8 apresentam opiniões similares em relação a mudanças emocionais que afetaram a rotina de estudos como desmotivação, falta de controle emocional, abalo emocional, desestímulo e insegurança.

Na questão 3 são identificadas as seguintes categorias: 


\section{IC1 - Categorias}

J) Dificuldades emocionais para estudar;

K) Alternativas para compensar a ausência do professor e colegas;

L) Dificuldade de adaptação a nova rotina de estudos.

\section{IC2 - Categorias}

M) A contribuição de professores e colegas é necessária para a aprendizagem;

N) Aulas práticas e presenciais são imprescindíveis para o curso técnico.

Na categoria J, os alunos A1, A2, A6 e A8 relatam que a ausência de professores e colegas provocaram mudanças e dificuldades emocionais nos momentos dedicados aos estudos, a saber, desânimo, falta de concentração e descontrole emocional. Na categoria K, os alunos A4, A5 e A7 tentaram compensar a ausência de professores e colegas com alternativas como visualização de videoaulas, estudo de livro didático, pesquisa na internet e consulta aos pais. Na categoria L, o aluno A3 relatou a dificuldade de adaptação de uma rotina de estudos advinda do ensino presencial para outra no ensino remoto. Na categoria M da IC2, os alunos A2 e A7 ressaltam a importância da contribuição de professores e colegas para a construção do conhecimento e aprendizagem. Na categoria $\mathrm{N}$, o aluno salienta que as aulas práticas e presenciais são imprescindíveis e o diferencial para o curso técnico.

Na questão 4 são identificadas as seguintes categorias:

\section{IC1 - Categorias}

O) Estresse emocional e cansaço;

P) Leveza, tranquilidade, esperança e descontração;

Q) Preocupação com os efeitos da pandemia.

\section{IC2 - Categorias}

R) Postura positiva;

S) Desmotivação por sobrecarga de atividades;

T) Evitar o tema da pandemia.

$\mathrm{Na}$ categoria $\mathrm{O}$, os alunos A1 e A4 relatam estresse emocional e cansaço dos membros da família como efeito da pandemia. Na categoria $\mathrm{P}$, os alunos A2, A5, A6, A7 e A8 declaram que as famílias tentar conviver na pandemia com leveza, tranquilidade, esperança e descontração, embora haja preocupação com a renda familiar e estudos. Na categoria Q, o aluno A3 destaca a preocupar familiar com os efeitos da pandemia. Na categoria R, o aluno A1 ressalta que a família procura agir com uma postura positiva. Na categoria $\mathrm{S}$, a aluna $\mathrm{A} 4$ declara que se sente desmotivada devido à sobrecarga de atividades e na categoria T, o A6 relata que a família evita falar sobre o tema da pandemia.

Na questão 5 são identificadas as seguintes categorias:

\section{IC1 - Categorias}

U) Frustração e perda de sentido em relação aos sonhos;

V) Esperança e esforço para a realização dos sonhos; 
W) Mudanças nas expectativas em relação aos sonhos.

\section{IC2 - Categorias}

X) Esperança de que o tempo ajudará na realização dos sonhos;

Y) Descrédito e dúvida em relação à formação;

Z) Resiliência e aprendizagem.

Na categoria U, os alunos A1, A5, A6, A7 e A8 convergem as opiniões sobre a frustração e perda de sentido nas expectativas em relação aos sonhos e projetos. Na categoria $\mathrm{V}$, os alunos A3 e A4 declaram que mantém a esperança e foco nos estudos para realizar os sonhos e projetos e, na categoria W, aluno A2 relata mudanças nas expectativas em relação sonhos e projetos por não estar estudando. Na categoria $\mathrm{X}$, os alunos A1, A2 e A7 acreditam e têm esperança de que o tempo contribuirá na realização dos sonhos e projetos. Na categoria Y, os alunos A3 e A5 apresentam descrédito e dúvida sobre a formação nesse momento de pandemia, o que poderá comprometer o futuro acadêmico e na categoria Z, o aluno A6 demonstra-se resiliente com a situação e declara que o momento é de aprendizagem e os sonhos podem esperar em favor de um bem maior.

Diante da análise exposta, serão apresentados no quadro 6 os DSCs elaborados a partir das ICs e categorias formuladas com base nas respostas dos participantes desta pesquisa.

Quadro 6 - DSCs produzidos.

\begin{tabular}{|c|c|c|}
\hline \multicolumn{2}{|c|}{ IC } & DSC \\
\hline \multirow{5}{*}{ Categorias } & A & A pandemia não acarretou em mim mudanças significativas. \\
\hline & B & A pandemia causou me dificuldades financeiras na família. \\
\hline & $\mathrm{C}$ & A pandemia tornou minha rotina agitada devido às tarefas domésticas e dificuldades de estudar adequadamente. \\
\hline & $\mathrm{D}$ & A pandemia levou as pessoas da família a ficarem próximas em função da quarentena. \\
\hline & $\mathrm{E}$ & A pandemia forçou meus irmãos a mim a ficarmos em quarentena enquanto os pais trabalham. \\
\hline \multicolumn{3}{|c|}{ Questão 2. Como tem sido sua rotina de estudos? } \\
\hline \multicolumn{2}{|c|}{ IC } & DSC \\
\hline \multirow{4}{*}{ Categorias } & $\mathrm{F}$ & A pandemia provocou mudanças na minha rotina de estudos. \\
\hline & G & A pandemia me levou a estudar por conta própria. \\
\hline & $\mathrm{H}$ & A pandemia causou-me pressão psicológica para estudar. \\
\hline & I & A pandemia provocou em mim mudanças emocionais. \\
\hline \multicolumn{3}{|c|}{ Questão 3. De que forma você está reagindo nos momentos de estudos diante da ausência dos professores e colegas de sala? } \\
\hline \multicolumn{2}{|c|}{ IC } & DSC \\
\hline \multirow{5}{*}{ Categorias } & $\mathrm{J}$ & A ausência dos professores e colegas causou-me dificuldades emocionais para estudar. \\
\hline & K & A ausência dos professores e colegas levou-me a procurar alternativas para compensar tal ausência. \\
\hline & $\mathrm{L}$ & A ausência dos professores e colegas gerou-me dificuldades de adaptação a nova rotina de estudos. \\
\hline & M & $\begin{array}{l}\text { A ausência dos professores e colegas prejudicou a minha aprendizagem, pois eles contribuem no processo de } \\
\text { aprendizagem. }\end{array}$ \\
\hline & $\mathrm{N}$ & Preocupou-me a ausência das aulas práticas e presenciais, pois são imprescindíveis para o curso técnico. \\
\hline
\end{tabular}


Research, Society and Development, v. 10, n. 2, e59710212923, 2021

(CC BY 4.0) | ISSN 2525-3409 | DOI: http://dx.doi.org/10.33448/rsd-v10i2.12923

\begin{tabular}{|c|c|c|}
\hline \multicolumn{2}{|c|}{ IC } & DSC \\
\hline \multirow{6}{*}{ Categorias } & $\mathrm{O}$ & A pandemia provocou em mim estresse emocional e cansaço. \\
\hline & $\mathrm{P}$ & A família tentou reagir com leveza, tranquilidade, esperança e descontração. \\
\hline & Q & A pandemia causou em mim preocupação com seus efeitos futuros. \\
\hline & $\mathrm{R}$ & A família tentou reagir com postura positiva. \\
\hline & S & A pandemia ocasionou em mim desmotivação por sobrecarga de atividades. \\
\hline & $\mathrm{T}$ & A família evitou o tema da pandemia. \\
\hline \multicolumn{3}{|c|}{ Questão 5. Em relação à expectativa dos seus sonhos ou projetos, como você está lidando com isso nesse contexto de pandemia? } \\
\hline \multicolumn{2}{|c|}{ IC } & DSC \\
\hline \multirow{6}{*}{ Categorias } & $\mathrm{U}$ & A pandemia me deixou com frustração e perda de sentido em relação aos sonhos. \\
\hline & $\mathrm{V}$ & A pandemia não afetou minha esperança e esforço para a realização dos sonhos. \\
\hline & $\mathrm{W}$ & A pandemia trouxe-me mudanças nas expectativas em relação aos sonhos. \\
\hline & $\mathrm{X}$ & Tenho esperança de que o tempo ajudará na realização dos sonhos. \\
\hline & $\mathrm{Y}$ & Estou com descrédito e dúvida em relação à formação. \\
\hline & $\mathrm{Z}$ & A pandemia me ensinou a ter resiliência e aprender com esse momento. \\
\hline
\end{tabular}

Fonte: Autores.

A questão 1 evidencia alguns aspectos da rotina familiar, afetada pela pandemia da Covid-19 como dificuldades financeiras na família, rotina agitada devido às tarefas domésticas e dificuldades de estudar adequadamente, levou as pessoas da família a ficarem próximas em função da quarentena, forçou os filhos a ficarem em quarentena enquanto os pais trabalham, enquanto que, em outro caso, não acarretou mudanças significativas.

$\mathrm{Na}$ questão 2, a rotina de estudos, de modo geral, sofreu mudanças, uma vez que os alunos relataram a pandemia provocou mudanças na rotina de estudos, levou-os a estudarem por conta própria, causou pressão psicológica para estudar e mudanças emocionais.

$\mathrm{Na}$ questão 3, a forma que os alunos estão reagindo nos momentos de estudos diante da ausência dos professores e colegas de sala ocasionou dificuldades emocionais para estudar, levou-os a procurar alternativas para compensar tal ausência, gerou dificuldades de adaptação a nova rotina de estudos, prejudicou a aprendizagem significativa, pois professores e colegas contribuem no processo de aprendizagem e preocupação na ausência das aulas práticas e presenciais, pois são imprescindíveis para a formação em se tratando de curso técnico.

$\mathrm{Na}$ questão 4, quando perguntados como alunos e familiares estão reagindo emocionalmente aos efeitos causados por essa situação de pandemia, as respostas foram diversas tais como estresse emocional e cansaço, a família tenta reagir com leveza, tranquilidade, esperança e descontração, preocupação com seus efeitos futuros, reação com postura positiva, desmotivação por sobrecarga de atividades e tentativa de evitar o tema da pandemia.

$\mathrm{Na}$ questão 5, em relação à expectativa dos seus sonhos ou projetos, os alunos declaram que a pandemia causou frustração e perda de sentido em relação aos sonhos, não afetou a esperança e o esforço para a realização dos sonhos, trouxe mudanças nas expectativas em relação aos sonhos, esperança de que o tempo ajudará na realização dos sonhos, descrédito e dúvida em relação à formação e resiliência e aprendizagem com esse momento.

\section{Considerações Finais}

Com base na metodologia do Discurso do Sujeito Coletivo fundada no constructo da teoria das Representações Sociais, neste estudo procurou-se reconhecer na fala de um grupo de alunos do $3^{\circ}$ ano do curso técnico em Agropecuária do 
Ensino Médio Integrado do IFNMG campus Januária as percepções, as angústias, as necessidades e os ideais desenvolvidos por eles enquanto veem a realidade ao seu redor ser mudada abruptamente pela pandemia da Covid-19.

Em nossa amostra, fica patente que nenhum aluno passará incólume aos desafios dolorosos de superar ou se adaptar aos formatos impostos pela nova realidade. Se por um lado temos aqueles que estão sucumbindo e não conseguindo se organizar para os estudos de forma autônoma, assumindo novos papéis na reorganização da rotina familiar, lidando com temores e inseguranças e cancelando seus projetos, por outro temos aqueles que mesmo numa postura mais otimista também estão se amoldando, reorganizando-se e fazendo ajustes para tentar prosseguir, pois compreendem que este é mais um momento de escolhas.

Importa destacar, que os DSCs em questão inferem que a "autonomia e a interação" são categorias relevantes a serem consideradas no trabalho pedagógico nas Instituições de ensino e no âmbito familiar, bem como objetos para pesquisas posteriores, reverberando a importância das relações humanas serem inseridas no debate nesse novo contexto de ensino. Assim, faz-se necessário atentar para o compromisso de, nos espaços institucionais de educação, ensinar sobre a compreensão humana, preparar para a vida, a enfrentar problemas e situações da vida real

Finalmente, ressalta-se a pressa com que se tem tentado fazer essa transposição do ambiente de ensino, desencadeado pelo status de distanciamento social. As tecnologias como mediadoras e as práticas online podem servir às novas necessidades da educação, mas distante de serem redentoras, não podem desmerecer ou subestimar o bom preparo ou a imprescindível qualificação dos principais atores do processo de ensino e aprendizagem, professores e alunos, principalmente por se tratar de um curso técnico integrado ao Ensino Médio, como é o caso dos alunos objeto deste estudo. Espera-se que, à medida em que avançamos nesse cenário pandêmico, os padrões de aula remota estabelecidos até então se transformem e se materializem em pedagogias apropriadas ao meio digital, que promovam interações determinantes para o desenvolvimento da aprendizagem e alcancem os alunos em sua singularidade e totalidade de experiências, valores e objetivos.

As conclusões a que chegamos ao final deste estudo podem ser consideradas preliminares diante de um contexto que apenas começou a se descortinar e que já tem se mostrado instável e por isso gerado muitas incertezas. Por ser incipiente, esse contexto se beneficia de todas as pesquisas e estudos que para ele voltem seu olhar. Da mesma forma que esta investigação joga luz sobre uma demanda surgida dessa realidade e da qual não podemos prescindir, já é possível elencar tantas outras e que podem figurar como sugestões para trabalhos futuros. Desse modo, consideramos importante que sejam realizadas investigações de metodologias empregadas e desenvolvidas no ensino médio integrado ao ensino técnico durante a pandemia do corona vírus, estudos sobre práticas metodológicas remotas bem sucedidas nos diversos níveis educacionais, desenvolvimento e ensino de metodologias e práticas educativas para o ensino remoto, estudos sobre o ensino e aprendizagem das disciplinas técnicas mediado por tecnologias no contexto do ensino médio integrado ao ensino técnico, estudos práticos de atendimento à demanda psicológica e organização de nova rotina para estudos remotos direcionados à capacitação de discentes da educação básica e suas famílias e a investigação das fragilidades dos currículos da Educação Profissional e Tecnológica ante a realidade remota e proposições de soluções para transposição e adaptação curricular. Portanto, inúmeras são as possibilidades de trabalhos que podem ser pertinentes e contribuir enormemente no campo da educação em nosso país e de forma especial na educação básica do ensino médio integrado ao ensino técnico, agregando qualidade, diminuindo as disparidades sociais e preparando os alunos para a vida.

\section{Referências}

Behar, P. A. (2020). O ensino remoto emergencial e a educação a distância. UFRGS. Jornal da Universidade. https://www.ufrgs.br/jornal/o-ensino-remotoemergencial-e-a-educacao-a-distancia/ 
Research, Society and Development, v. 10, n. 2, e59710212923, 2021

(CC BY 4.0) | ISSN 2525-3409 | DOI: http://dx.doi.org/10.33448/rsd-v10i2.12923

Bogdan, R. C., \& Biklen, S. K. (1994). Investigação qualitativa em educação. Tradução Maria João Alvarez, Sara Bahia dos Santos e Telmo Mourinho Baptista. Porto Editora.

Brasil. (2020). Ministério da Educação. Portaria MEC n. 343, de 17 de março de 2020, alterada pela Portaria MEC nº 345, de 17 de março de 2020. Brasília, DF, 2020. http://portal.mec.gov.br/component/content/article?id=88631.

Brasil. (2020). Ministério da Saúde. Portaria n. 188, de 3 de fevereiro de 2020. Declara Emergência em Saúde Pública de importância Nacional (ESPIN) em decorrência da Infecção Humana pelo novo Coronavírus (2019-nCoV). Brasília, DF, 2020. http://www.in.gov.br/web/dou/-/portaria-n-188-de-3-de-fevereirode-2020-241408388.

Brasil. (2020). Decreto n. 9.057, de 25 de maio de 2017. Regulamenta o art. 80 da Lei 9.394 de 20 de dezembro de 1996, que es tabelece as diretrizes e bases da educação nacional. Brasília, DF, 2017. http://www.in.gov.br/materia/-/asset_publisher/Kujrw0TZC2Mb/content/id/20238603/do1-2017-05-26-decreto-n-9057-de-25-de-maio-de-2017-20238503

Costa, K. (2020). Questões psicológicas podem dificultar o acompanhamento de aulas remotas, dizem alunos. UFRGS Jornal da Universidade. 2020. //www.ufrgs.br/jornal/estudantes-apontam-problemas-psicologicos-para-acompanhar-as-aulas-remotas/.

Jodelet, D. (2011). Aportes del enfoque de las representaciones sociales al campo de la educación. Traducão de María Matilde Balduzzi. Espacios en Blanco. Serie indagaciones, 21, 133-154.

Lakatos, E. M., \& Marconi, M. A. (2003). Fundamentos de metodologia científica. (5a ed.), Atlas.

Lefevre, F., \& Lefevre, A. M. C. (2014). Discurso do sujeito coletivo: representações sociais e intervenções comunicativas. Texto Contexto Enferm, vol.23, n. 2, 502-507. http://www.scielo.br/pdf/tce/v23n2/pt_0104-0707-tce-23-02-00502.pdf.

Lefevre, F. et. al. (2009). Discurso do Sujeito Coletivo, complexidade e auto-organização. Ciências e Saúde Coletiva. 14(4): 1193-1204.

Martins, A. C. S., \& Pereira, A. (2020). EAD: Oportunidades e desafios em tempos de pandemia. Canal do IFNMG no YouTube, 2020. https://www.youtube.com/watch?v=po_siUe0oKk\&feature=youtu.be.

Minayo, M. C. de S. (2004). O Desafio do Conhecimento. Pesquisa Qualitativa em Saúde. (8a ed.), Ed Hucitec.

Minayo, M. C. S. et al. (2002). Pesquisa Social: Teoria, método e criatividade. Vozes.

Moura, D. H. (2020). A Rede Federal e sua importância na atual conjuntura de pandemia. Canal do MEP SINASEFE no YouTube. https://www.youtube.com/watch?v=k0eavQ_6CGg\&t=5s.

OMS. (2020). Organização Mundial de Saúde declara Pandemia do novo Corona Vírus - COVID-19. https://www.unasus.gov.br/noticia/organizacaomundial-de-saude-declara-pandemia-de-coronavirus.

OPAS. (2020). Organização Pan-americana de Saúde, "Considerações sobre medidas de distanciamento social e medidas relacionadas com as viagens no contexto da resposta à pandemia de Covid-19”. https://iris.paho.org/bitstream/handle/10665.2/52045/OPASBRACOVID1920039_por.pdf?sequence=9.

Pedrosa, G. F. S., \& Dietz, K. G. (2020). Representações sociais de pais / responsáveis sobre educação a distância no contexto da pandemia COVID-19. Research, Society and Development, 9 (8), e88984921. https://doi.org/10.33448/rsd-v9i8.4921

Pereira. A. S. et al. (2018). Metodologia da pesquisa científica. UFSM. https://repositorio.ufsm.br/bitstream/handle/1/15824/Lic_Computacao_MetodologiaPesquisa-Cientifica.pdf?sequence $=1$.

Ramos, M. (2020). O ensino Médio Integrado frente ao contexto de pandemia. Canal do MEP SINASEFE no YouTube, 2020. https://www.youtube.com/watch?v=WV15n_5VDd8 .

Saviani, D. (2020). Ensino Remoto em tempos de pandemia. Visão da Pedagogia Histórico-Crítica. Canal do ADUNEB no YouTube, 2020. https://www.youtube.com/watch?v=egovuMOrd08.

Todos pela Educação. (2020). Nota Técnica: O retorno às aulas presenciais no contexto da pandemia da Covid-19. São Paulo, 2020. https://www.todospelaeducacao.org.br/_uploads/_posts/433.pdf?1194110764. 